\section{Determinants of knowledge and safety practices of occupational hazards of textile dye workers in Sokoto, Nigeria: a descriptive analytic study}

Nneka Christina Okafoagu, Mansur Oche, Kehinde Joseph Awosan, Hashim Bala Abdulmulmuni, Godwin Jiya Gana, Jessica Timane Ango, Ismail Raji

Department of Community Medicine, Usmanu Danfodiyo University, Sokoto Teaching Hospital, Sokoto State, Nigeria

\begin{abstract}
Textile dye workers are subject to occupational hazards on a daily basis due to exposure to precarious conditions in the workplace. This study aimed to assess the knowledge, attitude and safety practices and its determinants among textile dye workers in Sokoto metropolis, Nigeria. This is a descriptive cross-sectional study conducted among 200 textile dye workers and the respondents were selected by multi stage sampling technique. Data was collected using an interviewer administered questionnaire. Data was processed using SPSS IBM version 20 and analyzed using descriptive and inferential statistics. Majority of the respondents $(74.0 \%)$ had good knowledge of workplace hazards; $(81.0 \%)$ had positive attitude and only $20 \%$ observed all the safety practices. Formal education ( $\mathrm{P}=0.047)$; working less than 5 days a week $(\mathrm{P}=0.001)$ and permanent employment $(\mathrm{P}=0.013)$ were found to be determinants of respondents' knowledge and attitude towards workplace hazards. Although the respondents had good knowledge and positive attitude, their lack of observance of safety practices brings to fore the need for direct safety instruction and training and retraining of textile dye workers on workplace hazards and safety practices.
\end{abstract}

\section{Introduction}

Since antiquity, fabrics have been dyed with extracts from minerals, plants and animals but in 1856, scientists discovered synthetic dyes and over the years its effects have been an issue of great concern for environmental and public health professionals. ${ }^{1,2}$ In Nigeria, most people engaged in dye industries are unskilled and are exposed to several hazards during waxing, bleaching and dyeing of fabrics due to their contact with chemicals and synthetic dyes. ${ }^{3}$

According to the World Health Organization (WHO) global strategy on occupational health $2004,20-50 \%$ of textile workers are subjected to hazardous exposures in industrialized countries and the rate may even be higher in developing countries. ${ }^{4}$ In Nigeria, little is known about the knowledge of occupational hazards in textile dyeing though the workers are exposed to many hazards and risks that could be detrimental to their health. ${ }^{5}$ Due to insufficient knowledge on how to manage the risks, textile dye workers become vulnerable to occupational health hazards. ${ }^{6}$ Observing safe practices while using chemicals depend on appropriate attitude towards the associated risk factors which is dependent on the knowledge of the harmful effects of these chemicals. ${ }^{7}$ Nigeria is one of the countries in which industries are growing up and at the same time information concerning occupational safety to workers is minimal and as a result of this, the textile workers often fall victims of occupational health hazards. ${ }^{8}$ Though a lot of work has been done concerning textile workers mostly in Asia; ${ }^{9}$ Europe $^{10}$ and in America, only scanty data is available in Africa, particularly Nigeria and in Sokoto state, no such study has been done among textile dye workers and hence the need arises to explore this area. This study aimed to assess the knowledge, attitude towards workplace hazards; safety practices and its determinants among textile dye workers in Sokoto metropolis, Nigeria.

\section{Materials and Methods}

The study was carried out in Sokoto metropolis, Sokoto State, North-western Nigeria. The State has 23 Local Government Areas and 3 senatorial districts namely Sokoto East, Sokoto South and Sokoto North. ${ }^{11}$ It was a descriptive and analytic study carried out in April 2016. The study population comprised of textile dye workers in Sokoto metropolis. Textile dye workers, who had worked for 6 months in the textile/dye shops were eligible to participate in the study while workers solely involved in the administrative work in the textile/dye shops (not directly involved in the dyeing process) were excluded from the study. Using a proportion of respondents that had knowledge that dyes; hydrogen sulphite and caustic soda could cause some poisonous gas from a previous study among resist dye workers $(86.5 \%),{ }^{5} 200$ textile dye workers were recruited for the study using
Correspondence: Nneka Christina Okafoagu, Usmanu Danfodiyo University Teaching Hospital, P.M.B 2370, Sokoto, Sokoto State, Nigeria.

Tel.: +234.8035.924553.

E-mail: stixveno4520@gmail.com

Key words: Occupational hazards; determinants; textile dye workers; Sokoto.

Contributions: NCO, conception and design, acquisition of data, drafting the article, final approval of the version to be published; MOO, KJA, JTA, conception and design, critical revision of the article, final approval of the version to be published; HBA, conception and design, acquisition of data, critical revision of the article, final approval of the version to be published; GJG, conception and design, analysis and interpretation of data, drafting the article, final approval of the version to be published; IR, analysis and interpretation of data, drafting the article, final approval of the version to be published.

Conflict of interest: the authors declare no potential conflict of interest.

Received for publication: 15 February 2017.

Revision received:23 May 2017.

Accepted for publication: 29 May 2017.

This work is licensed under a Creative Commons Attribution NonCommercial 4.0 License (CC BY-NC 4.0).

(C) Copyright N.C.Okafoagu et al., 2017

Licensee PAGEPress, Italy

Journal of Public Health in Africa 2017; 8:664 doi:10.4081/jphia.2017.664

the formula for determination of sample size for descriptive studies $n=z^{2} p q / d^{2}$ after correcting for $90 \%$ attrition. A multi-stage sampling technique was used to select the respondents. Using a simple random sampling technique, 2 senatorial districts (Sokoto East and Sokoto South) were chosen out of the 3 senatorial districts in Sokoto State. The wards (where textile dyeing was done) in each selected metropolitan LGA were listed and four wards were selected by simple random sampling through balloting in each case (a total of 8 wards in the 2 LGAs). Systematic random sampling was used to enroll textile dye workers in the 8 selected wards. To achieve this, a comprehensive list of textile dye workers in the selected wards was sought from the association of textile dye workers and this was used as the sampling frame. Proportional allocation (PA) of the textile dye workers to be enrolled in the 8 wards was done. A semi-structured interviewer-administered questionnaire was used to assess the knowl- 
edge, attitude and safety practices of workers. The questions were adapted from previously validated tools with some modifications ${ }^{5,6,12-16}$ and was translated to Hausa (the local language in the communities) and back translated to English by two different scholars. The questionnaire was administered to the textile dye workers in Hausa language by the research assistants who were trained on the objectives of the study, data tools and interpersonal communication. There were 34 questions on knowledge addressing the subthemes: knowledge of chemicals used in workplace; knowledge of ways of exposure to chemicals; knowledge of organs affected by chemical use; knowledge of chemical and physical hazards; knowledge of safety practices and knowledge of personal protective equipment (PPEs). Correct answers to questions on knowledge was scored one (1) and incorrect ones and no response, nil ( 0$)$ and converted to percentages and scores were graded as poor knowledge $(<50 \%)$, fair knowledge $(50-74 \%)$ and good knowledge $(>75 \%)$. There were ten (10) questions on attitude which were assessed using Yes scored as 1 (one) and No and Don't Know scored as 0 (zero), these were converted to percentages and graded as positive attitude $(\geq 50 \%)$ and negative attitude $(<50 \%)$. Univariate, bivariate and multivariate analysis were carried out using IBM SPSS version 20. Pearsons'chi square was used to test associations between predictor and outcome variables followed by binary and multiple logistic regression to determine the predictors. Binary logistic regression using forced entry was used to compute the determinants of knowledge, attitude and safety practices. The output of the regression analysis was presented as Odds Ratio (OR) with 95\% confidence intervals. Results were presented in tables. The level of significance was set at $\mathrm{P}<0.05$. Ethical approval was obtained from the Ethical Committee of the Usmanu Danfodiyo University Teaching Hospital, Sokoto (UDUTH/HREC/ 2015/NO.302) and informed consent was obtained from the participants.

\section{Results}

All two hundred questionnaires were completely filled, returned and analyzed after validation (giving a response rate of $100 \%$ ).

\section{Section 1: Sociodemographic characteristics and work profile of respondents}

The mean age of the respondents was 27.54 \pm 9.01 years. All the respondents were males; $140(70 \%)$ were single and 93 $(46.5 \%)$ had secondary level education. Of the 200 respondents, $138(69 \%)$ were permanently employed; 144 (72\%) had worked for less than 10 years; $105(52.5 \%)$ worked for 6-7 days and $150(75 \%)$ worked less than 8 hours per day.

\section{Section 2: Knowledge of work place hazards}

Majority of the respondents 177 $(88.5 \%)$ knew that they were exposed to some hazards as textile dye workers; 149 $(74.5 \%)$ knew that the eyes could be affected by chemical use while only $88(44.0 \%)$ knew that ingestion was a route of exposure to chemicals in the workplace. One hundred and sixty-nine respondents $(84.5 \%)$ knew that use of chemicals in the workplace could cause skin burns and only 59 (29.5\%) did not know that they were exposed to excessive heat while working. A good proportion of the respondents $155(77.5 \%)$ had knowledge on use of PPEs during the dyeing process and $78(39 \%)$ knew that eye goggles could be used in textile dyeing. A high proportion of the respondents $(74 \%)$ had good knowledge of workplace hazards and safety practices (Table 1).

\section{Section 3: Attitude of respondents towards work place hazards}

More than half of the respondents 103 $(51.5 \%)$ felt that people worry more than necessary about the hazards associated in their workplace and $129(64.5 \%)$ felt the risks associated with chemicals/dyes were sufficiently controlled in the workplace A good proportion of the respondents 176 $(88 \%)$ felt that given the opportunity they would use further measures to protect their health in the workplace. A good proportion of the respondents $(81 \%)$ had positive attitude towards workplace hazards and safety practices (Table 2).

\section{Section 4: Respondents' safety practices}

More than half of the respondents 102 $(51.0 \%)$ read labels on containers 207 of chemicals while a few of the respondents 27 (13.5\%) did not wash their hands before eating or drinking. A good proportion of respondents $175(87.5 \%)$ changed their clothes after work as a safety practice and only $20 \%$ observed all safety practices (Table 3 ). A high proportion $117(60.6 \%)$ of the respondents always used hand gloves while eye goggles and facemasks were never used by a good percentage of the respondents $(59.6 \%$ and $63.5 \%$ ) respectively.

\section{Section 5: Determinants of knowl- edge and safety practices}

There was a relationship between knowledge of workplace hazards and age $(\mathrm{P}=0.022)$; the level of education $(\mathrm{P}=0.047)$; marital status (0.038) and days worked per week $(<0.001)$ of the respondents in the study. The key determinants of knowledge in the study were days worked per week and level of education. Respondents who worked for less than 5

Table 1. Grading of Respondents' knowledge of workplace hazards $(n=200)$.

\begin{tabular}{lc}
\hline Knowledge grading & N. (\%) \\
Poor knowledge $(<50 \%)$ & $32(16.0)$ \\
Fair knowledge $(50-74 \%)$ & $20(10.0)$ \\
\hline Good knowledge $(\geq 75 \%)$ & $148(74.0)$ \\
\hline
\end{tabular}

Table 2. Grading of Attitude towards workplace hazards $(n=200)$.

\begin{tabular}{lr} 
Attitude grading & N. $(\%)$ \\
Negative attitude $(<50)$ & $38(19.0)$ \\
Positive attitude $(\geq 50)$ & $162(81.0)$ \\
\hline
\end{tabular}

Table 3. Respondents' workplace safety practices $(n=200)$.

\begin{tabular}{ll} 
Safety practices & N. (\%) \\
Read labels on containers of chemical & $102(51.0)$ \\
Wear gloves when working with chemicals & $163(81.5)$ \\
\hline Wash hands with soap and water after work & $172(86.0)$ \\
Wash hands before eating or drinking & $173(86.9)$ \\
\hline Cover lid of container after chemical use & $106(53.0)$ \\
Wash and bath after work & $162(81.0)$ \\
\hline Change clothes after work & $175(87.5)$ \\
Keep worksite clean & $157(78.5)$ \\
\hline Store chemicals in a separate place & $159(79.5)$ \\
Use or wear PPEs & $193(96.5)$ \\
\hline Clean protective clothing & $166(83.0)$ \\
\hline
\end{tabular}


days per week were 5 times more likely to have good knowledge compared to others $(\mathrm{P}<0.001)$ while those whose lowest level of education was primary school (formally educated) were 5 times more likely to have good knowledge compared to their counterparts $(\mathrm{P}=0.047)$ (Table 4).

There was a relationship between attitude towards workplace hazards and level of education ( $\mathrm{P}=0.004)$; duration of work $(\mathrm{P}=0.015)$ and days worked per week $(\mathrm{P}=0.029)$. The key determinant of attitude was found to be level of education in the study. Respondents whose lowest level of education was primary school (formal education) were 17 times more likely to have a positive attitude than those without formal education (those with no form of education or quaranic education) $(\mathrm{P}=0.008)$ (Table 5).

There was no relationship between the ages of the respondents; level of education; work days per week; work hours per day and safety practices in the study.

\section{Discussion}

Millions of textile workers are occupationally exposed to dyes/chemicals in the world but little is known about their knowledge towards the effects of dye/ chemicals on their health especially in the developing world, Nigeria inclusive. ${ }^{17}$ Over $80 \%$ of the respondents in the study knew they were exposed to hazards in the workplace. This is not surprising as a good percentage of the respondents had primary school education as their lowest level of education and this could account for the high knowledge of exposure to hazards. This is comparable with studies done in Abeokuta, Nigeria; India and Thailand which showed that the workers had knowledge about the hazards they were exposed to at work. ${ }^{5,14,18}$ When the respondents were questioned about the possible routes of exposure to chemicals in the workplace, over $70 \%$ of the workers claimed that the skin was the most common route of entry followed by the inhalation route, then the mouth. It is not surprising that the skin is the most common route as the chemical substances used by textile dye workers can cause acute exposures which readily manifest as skin burns and skin itching. A study from Pakistan in the textile industry also found that majority of the workers were exposed to chemicals through the skin $(52.08 \%)$, while fewer $(26.04 \%)$ workers were exposed to chemicals through the mouth. ${ }^{19}$ This is however dissimilar to a study in the Gaza strip where the workers identified inhalation as the most common route of exposure to chemicals in the workplace. ${ }^{20}$ Almost all of the respondents knew that the skin was affected by chemicals used in their workplace. This is similar to a study in India which found that all the textile workers agreed that dyes could affect the skin. ${ }^{17}$ Similarly, about half of the respondents knew that chemicals could affect their lungs and this is in consonance with a study in India where $51 \%$ of the textile workers opined that dyes could affect the lungs. ${ }^{17}$ The study showed that over $80 \%$ of respondents knew that hand washing was an important preventive measure. A study in Nepal also found that $88.5 \%$ knew about the importance of hand washing agreeing with the findings of the study. ${ }^{21}$ Also, over $70 \%$ of the respondents had knowledge of use of PPEs. This finding is similar to that obtained in studies in Ethiopia and India where $72.3 \%$ and $63 \%$ of the respondents had knowledge of use of PPEs. ${ }^{14,22}$ Respondents had an above average overall knowledge of workplace hazards and safety practices $(74.0 \%$ had good knowledge). This is encouraging considering that several studies have reported far lower proportion of good knowledge in Abeokuta (3.7\%), Vietnam (3.72\%), Iran (10.5\%), Hong Kong (20.4\%) and Thailand (34.1\%). 5, 15,18,23,24

Over $80 \%$ of the respondents in the study had overall positive attitude towards workplace hazards and safety practices. This is favorable as psychological research has shown that an individual's attitude towards personal responsibility for safety is closely related to their likelihood of suffering a workplace accident or disease. ${ }^{25}$ Therefore, the likelihood of these workers suffering a workplace hazard can be said to be less as they have positive attitude towards workplace hazards and safety practices. This is in line with a study carried out in Iran 267 which showed that $75.7 \%$ of the organic chemical workers had positive attitude towards 268 occupational health and safety. ${ }^{24}$ Studies in Oyo State, Nigeria (16.7\%), Hong Kong (38.4\%), India (50\%) and Vietnam $(4.2 \%)$ have shown garment workers with a far lower positive attitude towards workplace hazards. ${ }^{12,15,23,26}$

Of the safety practices, over $50 \%$ of the respondents read labels on containers of chemical, more than $80 \%$ wore gloves when working with chemicals and washed hands before eating or drinking while over $70 \%$ covered the lid of container after chemical use. This is in consonance with a study among printing workers in Hong Kong that found that $49.7 \%$ of the respondents read labels on containers; $75.6 \%$ used gloves; $56.1 \%$ washed hands before eating and drinking and $85 \%$ covered lids of containers after use. ${ }^{15}$ Despite this, only $20 \%$ of the respondents observed all the safety practices. This appears worrisome as maintaining a safe and healthy environment which is a fundamental right of every worker would be undermined if only few workers observed all the safety practices. A study in Hong Kong among printing workers also found that $22 \%$ of the respondents adopted all the safety practices. ${ }^{15}$ Even though over $90 \%$ of the respondents reported using PPEs, less than $20 \%$ of the workers always used any other form of protective device (eye googles, face mask and apron). This is comparable with studies done in Kwara and Edo states which indicated that less than $15 \%$ of the workers always used any form of protective device, while less than $5 \%$ of the workers wore face masks or protective clothing/boots at work. ${ }^{27,28}$ Also, a study among small industries in Saudi Arabia found that about $12 \%$ of the workers used personal protective measures all the time

Table 4. Multinomial regression of factors associated with knowledge of workplace hazards and safety practices.

\begin{tabular}{lccc}
\hline Variables & OR & $95 \%$ CI & P-value \\
Age of respondent ( $\leq 25$ years vs 25 years) & 1.19 & $0.35-4.12$ & 0.780 \\
Educational level (formal $v$ s informal) & 5.23 & $1.02-26.84$ & 0.047 \\
\hline Employment type (permanent vs temporary) & 0.39 & $0.19-0.82$ & 0.013 \\
Days worked per week ( $\leq 5$ days $v$ s $>$ 5days) & 5.83 & $2.39-14.27$ & 0.001 \\
\hline
\end{tabular}

Table 5. Logistic regression of factors associated with Attitude towards workplace hazards and safety practices.

\begin{tabular}{lccc} 
Variables & OR & $95 \%$ CI & P-value \\
Age of respondent ( $\leq 25$ years $v s>25$ years) & 1.73 & $0.81-3.69$ & 0.16 \\
Educational level (formal $v$ informal) & 17.03 & $2.09-139.00$ & 0.008 \\
\hline Duration of work ( $\leq 10$ years $v s>10$ years) & 1.23 & $0.76-2.00$ & 0.39 \\
Days worked per week $(\leq 5$ days $v s>5$ days) & 0.58 & $0.27-1.26$ & 0.17 \\
\hline
\end{tabular}


while $60 \%$ did not use any. ${ }^{13}$ Although a good proportion of the workers had good knowledge and positive attitude towards work place hazards, only $20 \%$ observed safety practices and this could be due to lack of supervision of workers by employees and lack of provision of basic amenities such as water for washing after work and lack of provision of PPEs for use at the workplace. Probably if these measures are put in place, the workers would begin to observe the safety practices.

Workers with formal education were found to be more knowledgeable about work place hazards. Education empowers workers to prevent work related hazards and without education they would not be able to understand and adopt the occupational health measures and practices. ${ }^{29} \mathrm{~A}$ study in Pakistan among textile workers also found that educated workers had more knowledge and there was a direct relationship between education of workers and occupational health and safety knowledge. ${ }^{30}$ This is similar to the findings in this study. Education was the only significant factor that determined positive attitude. Respondents who had primary school education as their lowest level of education (formal education) were 17 times more likely to have positive attitude. However, a study among printing workers found that only age was the significant factor found to be associated with appropriate attitude. ${ }^{15}$ No factors were found to be determinants of safety practices in this study.

\section{Conclusions}

Although the respondents had good knowledge and positive attitude, their lack of observance of safety practices brings to fore the need for direct safety instruction and training and retraining of textile dye workers on workplace hazards and safety practices.

\section{References}

1. Baker EL. A review of recent research on health effects on human occupational exposure to organic solvents. A critical review. J Occup Med 1994;36:107992.

2. Brautbar JD, Williams J. Industrial solvents and liver toxicity: risk assessment, risk factors and mechanisms Int J Hyg Environ Health 2002;205:479-80.

3. Ogunduyile SR. Cottage dyeing industry and environmental hazards created by the use of commercial dyes and chemicals. Ile-ife. J arts \& ideas 2001; 17:45-51.

4. WHO. Global strategy on occupational health for all- The way to health at work. 2004; 1 - 15 .

5. Akintayo WL. Knowledge, attitude and practice on the use of PPE by traditional resist fabric workers in Abeokuta; Nigeria. Kuwait chapter of Arabian journal of business \& management review. 2013; 2:27 - 37 .

6. Motbainor A, Kumie A, Melkamu YA. Assessment of knowledge and practice on safety information among factory workers. A Thesis submitted to the school of graduate studies of Addis Ababa University in partial fulfillment of a requirement for the degree of masters in public health. 2007:1-69.

7. Chiabhlaem T. "Occupational health and safety (Thailand)". 2011. Available online at:http://thongchai99.wordpress.com/ [cited 2015, February 3]

8. Bankole AR. Effective labour inspection as a correlate 318 of occupational health and safety of factory workers in Ogun State, Nigeria. Nig J Soc Work Edu. 2010; 9:1-3.

9. Christiani DC, Wang XR. Longitudinal changes in pulmonary function and respiratory symptoms in cotton textile workers. Am J Respiratory Critical Care Med. 2001; 163:847-53.

10. Simpson JC, Niven RM, Pickering CA, et al. Prevalence of predictors of work related respiratory symptoms in workers exposed to organic dusts. Occupational Env Med. 1998; 55:668 - 72.

11. Niyogi AK \& Strother JM. Dyeing, printing and finishing in 89 textile goods industry. Encyclopedia of Occupational Health and Safety.3rd edition; Part xiv. Available on www.iloencyclopaedia.org/part-xiv/dyeing-printing \& finishing. [Accessed August 12, 2014].

12. Paramasivam P, Raghavan PM, Srinivasan PD, Kumar GA. Knowledge, attitude, and practice of dyeing and printing workers. Indian J Community Med: official publication of Indian Association of Preventive \& Social Medicine. 2010; 35:498-501.

13. Taha AZ. Knowledge \& practice of preventive measures in small industries in Al- Khobhar. Saudi Med J. 2000; 21:740 - 5.

14. Parimalam P, Kamalamma N, AGK. Knowledge, attitude and practice related to occupational health problems among garment workers in Tamil Nadu; India. J. Occup Health. 2007; 49:528 34

15. Tak-Sun Yu I, Lee LI, Wong WT.
Knowledge, attitude and practice regarding organic solvents among printing workers in Hong Kong. J Occup Health. 2005; 47:305 - 10.

16. Ahmed HO, Newson-Smith MS. Knowledge and practices related to occupational hazards among cement workers in the UAE. J Egypt Public Health Assoc. 2010; 85:149-67.

17. Parimalam P, Raghavan PM, Srinivasan OP, Kumar AG. Knowledge, attitude and practice of dyeing and printing workers. Indian J Comm Med. 2010; 35:498 - 501.

18. Uma L, Nuntavarn V, Sasitorn T. Safety and health in the petrochemical industry in Map Ta Phut; Thailand. J Occupl Health. 2011; 53:384-92.

19. Asuzu MC. Occupational Health: A Summary introduction and outline of principles. 2nd ed. Ibadan (Nigeria). Africa links books.2002; 1 - 14: 34 - 7.

20. Abdel Monem HL, Adnan IA, Abed AlRahman I, et al. Exposure of gasoline station workers to leaded gasoline in the Gaza strip: Awareness and self-reported symptoms. Annals of Alquds medicine. 2010; 6:1-10.

21. Neupane D, Khanal V, Ghimre K, Leppin A. Knowledge, attitude and practices related to avian influenza among poultry farm workers in Nepal: a cross sectional study. BMC Infectious Diseases. 2012; 12:76.

22. Tetemke D, Alemu K, Tefera Y, et al. Knowledge and practices regarding safety information among textile workers in Adwa town, Ethiopia. Science Postprint. 2014; 1:1-5.

23. Dat CT, Siriwong W. Assessment of KAP of using of PPE in rattan craftsmen at the trade village; Kienxuong district; Thiabinh province; Vietnam. J Science; Hue University. 2010; 61:51-6.

24. Nasab HS, Ghofranipour F, Kazemnejad A, et al. Evaluation of knowledge, attitude and behaviour of workers towards occupational health and safety. Iranian J Public Health. 2009; 38; 2:125 - 9 .

25. One test. Work safety assessment [January 4, 2014]. Available from: www.onetest.com.au/home/work-safety.

26. Bolaji AO. Analytical study of carpenters' attitude towards safety and occupational health practice in Oyo state. J Hum Ecol. 2005; 18:99-103.

27 Osagbemi KG, La-Kadiri RT, Aderibigbe SA. Awareness of occupational hazards, health problems and safety measures among sawmill workers in North Central Nigeria. TAF Prev Med Bull. 2010; 9:325 - 8

28. Ugheoke AJ, Ebiomoyi MI, Iyawe VI. 
Influence of smoking on respiratory symptoms and lung functions indices in sawmill Workers in Benin City. Nig J

Physiol Scien. 2006; 21:49 - 54.

29. Hogstedt C, Pieris B. Occupational safety and health in developing countries: Review of strategies, case studies and a bibliography. The National Institute for working life. 2000; 17.

30. Malik N, Maan AA, Pasha ST, et al.
Role of hazard control measures in occupational health and safety in the Textile Industry of Pakistan. Pak J Agri Sci. 2010; 47:72 - 6 